\title{
Deformation behavior of high yield strength - high ductility ultrafine-grained 316LN austenitic stainless steel
}

D.M. Xu ${ }^{1}$, G.Q. $\mathrm{Li}^{1,2}$, X.L. Wan ${ }^{1,2^{*}}$, R.L. Xiong ${ }^{3}$, G. Xu ${ }^{1}$, K.M. Wu ${ }^{1}$, M.C. Somani ${ }^{4}$, R.D.K. Misra ${ }^{5}$

${ }^{1}$ The State Key Laboratory of Refractories and Metallurgy, Wuhan University of Science and Technology, Wuhan 430081, China

${ }^{2}$ Key Laboratory for Ferrous Metallurgy and Resources Utilization of Ministry of Education, Wuhan University of Science and Technology, Wuhan 430081, China

${ }^{3}$ School of Mechanical and Electrical Engineering, Wuhan Institute of Technology, Wuhan 430205, China

${ }^{4}$ Faculty of Technology, Centre for Advanced Steels Research, University of Oulu, Oulu 90014, Finland

${ }^{5}$ Laboratory for Excellence in Advanced Steel Research, Department of Metallurgical, Materials, and Biomedical Engineering, University of Texas at El Paso, El Paso, TX 79968, USA

Corresponding author: X.L. Wan

Tel.: 86-27-68862665, Fax: 86-27-68862665, Email: wanxiangliang@wust.edu.cn

\begin{abstract}
$\underline{\text { Abstract }}$
The concept of phase reversion annealing involving extensive cold deformation of metastable austenite to strain-induced martensite, followed by annealing at slightly elevated temperature, developed by Misra's group in recent years [2-5] was used to obtain ultrafine-grained structure in a $316 \mathrm{LN}$ austenitic stainless steel. The primary objective of this study is to elucidate the deformation mechanisms. The study suggested that an average austenite grain size in the ultrafine regime of $\sim 2.0 \mu \mathrm{m}$ can be obtained using the experimental conditions described in the study, which is $\sim 6$ times finer than the grain size of commercial $316 \mathrm{LN}$ steel. The grain refinement led to high yield strength in ultrafine-grained $316 \mathrm{LN}$ steel without any significant compromise in ductility. The high plasticity of ultrafine-grained $316 \mathrm{LN}$ steel is attributed to the presence of mechanical twins.
\end{abstract}

Keywords: austenitic stainless steel; grain refinement; mechanical property; deformation mechanism; reversion annealing 


\section{Introduction}

Austenitic stainless steels exhibit excellent corrosion resistance and are commonly used in nuclear power plants, gas turbine components, underwater pipelines etc. The yield strength of commercial austenitic stainless steels is low because of coarse and soft $\gamma$ phase [1]. There is a significant interest in increasing the yield strength of commercially available austenitic stainless steels, so that these materials can be widely exploited for structural applications. Grain size refinement is an effective method to increase the yield strength without significantly impairing the plasticity [1]. The concept of phase reversion annealing developed by Misra's group in recent years [2-5], involving extensive cold deformation of metastable austenite to generate strain-induced martensite, followed by annealing, was used to obtain nanograined/ultrafine-grained (NG/UFG) austenitic stainless steels with high yield strength and good plasticity [2,5]. Previous studies indicated that yield strength of the order of $880 \mathrm{MPa}, 900 \mathrm{MPa}$ and $1150 \mathrm{MPa}$ were obtained in 301LN [2], 204Cu [6] and Ni-free [7] austenitic stainless steels respectively, when austenitic grains were refined to NG/UFG structure by the ingenious approach of phase reversion adopted by

Misra et.al. [2-5]. Interestingly, the corresponding elongation values of NG/UFG austenitic stainless steels were in the range $\sim 47 \%-21 \%$. The excellent plasticity was attributed to transformation-induced plasticity (TRIP) and/or twinning-induced plasticity (TWIP) effect during tensile straining.

Type 316 austenitic stainless steels have high content of $\mathrm{Cr}$, Ni and $\mathrm{Mo}$, which provide certain specific properties, such as corrosion resistance, high toughness at 
cryogenic temperatures, etc. However, there is also a strong need to improve yield strength in 316 austenitic stainless steels, besides reducing the alloying content. Strengthening methods [1] such as alloying with nitrogen [8], equal-channel angular pressing [8] and mechanical attrition [9] have been used to increase the strength of 316 austenitic stainless steels. The approach of phase reversion annealing is considered to be an appropriate process to obtain high yield strength in 316 austenitic stainless steels with in situ formed fine-grained structure. A few studies are devoted to microstructural evolution and variation in mechanical property of 316 austenitic stainless steels during/after cold rolling and annealing process [10-13].

The objective of the study described here is to obtain UFG 316LN austenitic stainless steels with high yield strength and high ductility combination using phase reversion annealing approach, and study the deformation behavior of UFG steel during tensile straining and compare the deformation behavior with that of the commercial 316LN austenitic stainless steel counterpart.

\section{Experimental procedure}

The starting material used in this study was a commercial type 316LN austenitic stainless steel of $\sim 3 \mathrm{~mm}$ thickness and the chemical composition (in weight percent) of steel is listed in Table 1. The strips were cold rolled at room temperature to $90 \%$ reduction in thickness in a pilot plant and austenite transformed into martensite. Next, the samples were placed in a furnace under argon atmosphere for isothermal annealing at $900{ }^{\circ} \mathrm{C}$ for 2 minutes to obtain complete reversion to austenite from deformed martensite and the average grain size of austenite was in the UFG regime. 
Following annealing, the sample was immediately quenched in water to room temperature to avoid precipitation. Microstructural characterization was carried out with the aid of a scanning electron microscope (SEM, Nova400Nano) and a transmission electron microscope (TEM, JEM-2100). The crystallographic orientation and the quantitative evaluation of grain size of selected reversion annealed samples were conducted by electron backscattered diffraction (EBSD) analysis.

The uniaxial tensile test was carried out at room temperature at an engineering strain rate of $5 \times 10^{-4} \mathrm{~s}^{-1}$. Samples of dimensions $140 \times 20 \mathrm{~mm}$ and $65 \mathrm{~mm}$ gage length were used. To study the deformed microstructure as a function of strain, the tensile tests were interrupted at selected engineering strain of 0.1 . The area close to the highly stressed region within the gage length was used for the preparation of TEM foils from a number of tensile-tested specimens for each test condition. The specimens were examined in a JEM-2100 TEM operated at $200 \mathrm{kV}$. Thin foils were prepared by twin-jet electropolishing of $3 \mathrm{~mm}$ disks, punched from the specimens, using a solution of $10 \%$ perchloric acid in acetic acid as electrolyte. X-ray diffraction (XRD) analysis (X'Pert PRO MPD) was carried out to identify the phase structure after cold rolling and annealing process.

\section{Results}

\subsection{Microstructure}

The SEM and TEM micrographs and XRD analysis describing the microstructural evolution in 316LN austenitic stainless steel during cold rolling and subsequent reversion annealing process are presented in Figs. 1-4. Fig. 1 shows the 
microstructure of commercial 316LN steel at different magnifications. Fig. 1a shows the coarse-grained structure in commercial $316 \mathrm{LN}$ stainless steel. The TEM micrograph in Fig. 1b indicated a large number of dislocations intersecting each other in the interior of the grain. In some regions, stacking faults (SF) were observed, as shown in Fig. 1c. The corresponding diffraction pattern indicated that the microstructure was face-centered cubic (FCC) austenite, which was confirmed by selected area diffraction analysis (Fig. 1d) and also by X-ray diffraction (Fig. 2).

The strain-induced transformation of austenite to martensite occurred during cold rolling [2]. Fig. 3a shows that a significant fraction of austenite transformed to martensite after $90 \%$ cold reduction. The martensite laths were oriented along the rolling direction. High magnification bright and dark field TEM micrographs revealed that the microstructure consisted of martensite, as presented in Figs. $\mathbf{3 b}$ and $\mathbf{3 c}$. The width of martensite laths was $\sim 200 \mathrm{~nm}$ and the phase was identified as body-centered cubic (BCC) structure by the corresponding diffraction pattern in Fig. 3d. Interestingly, the volume fraction of martensite in Fig. 2 analyzed by XRD was 46\%, and comparable to $316 \mathrm{LN}$ austenitic stainless steel [10], but less than that in $304 \mathrm{~L}$ austenitic stainless steel [14] subjected to similar degree of cold reduction. This is because of higher stability of $316 \mathrm{LN}$ in comparison to 304L, while metastable $301 \mathrm{LN}$ austenitic stainless steel showed complete transformation to martensite even at $75 \%$ cold rolling reduction [2].

Fig. 4 shows the final microstructure in $316 \mathrm{LN}$ austenitic stainless steel after reversion annealing at $900{ }^{\circ} \mathrm{C}$ for 2 minutes. It shows that the microstructure was 
uniform with small equiaxed austenite grains (Fig. 4a). A number of annealing twins were observed in Fig. 4a. The straight annealing twins divide the austenite grains into small regions. Furthermore, SFs were also observed in the microstructure, as depicted in Figs. 4b and 4c. The electron diffraction pattern in Fig. 4d revealed that the microstructure in Fig. 3c was reverted FCC structure. The content of $\gamma$ phase based on XRD patterns in Fig. 2 was more than 97\%, and martensite could not be observed via TEM. The microstructure of 316LN stainless steel after phase reversion annealing treatment was essentially austenite.

The austenite grain size, which is important for studying the microstructural evolution during tensile straining [4,5] was measured by EBSD. The boundary with a misorientation greater than $15^{\circ}$ can be regarded as the boundary of two crystallographic grains. The crystallographic grains were assumed to be spherical to facilitate grain size measurement. Figs. 5a and 5d are the EBSD orientation image maps of $316 \mathrm{LN}$ steel before and after phase reversion annealing treatment, respectively. The corresponding statistical distribution of grain size is presented in Figs. 5b and 5e. The grain size before and after phase reversion annealing was $\sim 12.6$ $\mu \mathrm{m}$ and $\sim 2.0 \mu \mathrm{m}$, respectively. The grain size in $316 \mathrm{LN}$ steel after annealing treatment was smaller and more uniform, defined as UFG steel. Meanwhile, the inverse pole maps in transverse direction revealed that the maximum density of grains near [101] orientation were 1.43 and 1.83 respectively, indicating the possibility of a small degree of texture in UFG and commercial steels. The possibility of small degree texture in UFG steel is attributed to high temperature annealing treatment [15]. 


\subsection{Mechanical behavior}

The engineering stress-strain curves are presented in Fig. 6a and the tensile properties summarized in Table 2. The yield strength of UFG steel was $994 \mathrm{MPa}$, which is 3.5 times higher than the commercial $316 \mathrm{LN}$ steel counterpart. Furthermore, both UFG and commercial steels exhibited excellent plasticity with a total elongation of $40 \%$ and $52 \%$, respectively. It is noted in Fig. 6 a that the behavior of commercial steel appeared to show continuous yielding, whereas, UFG steel was characterized by a distinct yield point. Corresponding true tensile stress-strain plots are presented in Fig. 6b. There was near continuous increase of true stress with true strain for both UFG and commercial steels. In order to analyze the subtle differences, the variation in instantaneous strain hardening rate calculated from the true stress-strain plot is presented in Fig. 6c. In the case of commercial steel, the strain hardening rate decreased rapidly (stage A) and then relatively slowly (stage B) with increased strain until the onset of necking. However, in the UFG steel, the strain hardening rate decreased rapidly during the initial period (stage A), followed by a rapid increase (stage B). With increase in strain, the strain hardening rate was almost constant (stage C). Then, the strain hardening rate increased gradually (stage D), attaining a high strain hardening coefficient. Finally, the strain hardening rate decreased (stage E) until fracture.

\subsection{Deformation behavior}

The variation in mechanical properties and strain hardening rate are related to microstructural evolution and deformation mechanism in austenitic stainless steels. 
The microstructural evolution in UFG and commercial steels with 0.1 strain are presented in Figs. 7 and 8. Fig. 7 summarizes the representative TEM micrographs of the deformed microstructure associated with 0.1 engineering strain for the commercial steel. There were numerous dislocations (Fig. 7a) and fine shear bands (Figs. 7b and 7c). The á-martensite laths were also observed (Fig. 7d) and the thickness of ó-martensite laths was in the range of $\sim 120 \mathrm{~nm}$ to $370 \mathrm{~nm}$. The shear bands and ó-martensite act as barrier to dislocation motion.

The deformation structure for UFG steel is presented in Fig. 8. A large number of mechanical twins were observed (Figs. 8a and 8b). Furthermore, twins separated the grain into small regions (Figs. 8d and 8e). These twins are clearly different from the annealing twins present in UFG steel before tensile test (see Fig. 4a, for instance), suggesting that they are deformation-induced twins. The diffraction pattern in Figs. 8c and $\mathbf{8 f}$ indicated that the deformed microstructure is to FCC.

\section{Discussion}

It is evident from Fig. 5 that the austenite grains were effectively refined by phase reversion annealing approach. The austenite grain size in UFG steel was $2.0 \mu \mathrm{m}$, and was 6.3 times finer than the commercial steel. Furthermore, the yield strength of UFG steel was increased to $994 \mathrm{MPa}$, which is 3.5 times higher than the commercial 316LN steel (Table 2). Interestingly, both UFG and commercial austenitic stainless steels had excellent plasticity (40\% 52\%), thus enabling high strength to be obtained in UFG steel without affecting ductility.

The tensile deformation mechanism has an important influence on plasticity [16]. 
However, it is known that the deformation mechanisms are closely related to stacking fault energy (SFE) in austenitic steels [16,17]. Lee et al. [17] examined the SFE and deformation microstructure in austenitic steel and identified that TRIP occurred in austenitic steel with low SFE (SFE $<15 \mathrm{~mJ} / \mathrm{m}^{2}$ ) and deformation twins in austenitic steel with high SFE (SFE $>20 \mathrm{~mJ} / \mathrm{m}^{2}$ ). When the SFE was between 15 to $20 \mathrm{~mJ} / \mathrm{m}^{2}$, the deformation microstructure may comprise either transformed martensite or mechanical twinning or both. The SFE of $316 \mathrm{LN}$ austenitic stainless steel is $~ 18.9$ $\mathrm{mJ} / \mathrm{m}^{2}$, calculated from the composition based equation of Brofman and Ansell [18]. The deformation mechanism in commercial $316 \mathrm{LN}$ austenitic stainless steel was strain-induced ó-martensite (Fig. 7).

In contrast to commercial steel, the excellent elongation of UFG steel was due to mechanical twinning (Fig. 8). This can be discussed as follows:

(1) First, it is generally accepted that SFE is affected by chemical composition, strain rate and temperature [19]. Also, some studies [20] reported that grain refinement increases SFE. But SFE is not affected by grain size, considering that grain boundaries have no role to play in the variation of SFE. Thus, the explanation of SFE varying with grain size at constant strain rate and temperature is considered untenable because the SFE per se is constant for a given material.

(2) Second, the orientation of austenite is also an important factor that influences strain-induced transformation in austenitic steels. Previous study [21] indicated that martensite formation has no significant orientation dependence during the early stage of deformation. Whereas $\gamma$ grains with tensile direction nearly parallel to the $<111>\gamma$ 
direction may preferentially nucleate $\varepsilon$-martensite at high strain. Then $\varepsilon$-martensite transforms to ó-martensite immediately [6]. Gutierrez-Urrutia et al. [22] indicated that deformation twinning occurs in grains oriented close to $<111>/ /$ tensile axis direction, when the twinning stress is greater than the slip stress. Grain rotation promotes more twin variants for tensile deformation [23]. In the present study, the possibility of a small degree of texture in UFG steel is attributed to high temperature annealing [15], and inhibition of strain-induced martensite transformation is not the underlying reason.

(3) Last, the interplay between grain size and austenite stability in austenitic steels has been investigated and revealed that grain refinement increases the stability of austenite $[5,24,25]$. The $\mathrm{M}_{\mathrm{d} 30}$ temperature (where $50 \%$ ó-martensite is present after $30 \%$ tensile deformation) based on Nohara's equation [26] indicative of mechanical stability of austenite is presented in Table 2. It indicates that grain refinement can decrease the $\mathrm{M}_{\mathrm{d} 30}$ temperature from $7.6^{\circ} \mathrm{C}$ in commercial steel to $0.1^{\circ} \mathrm{C}$ in UFG steel, which inhibits strain-induced martensite formation in metastable austenite.

In summary, both commercial and UFG 316LN austenitic stainless steels exhibited good ductility. However, there was an important difference in the deformation behavior. For commercial steel, deformation-induced martensite transformation contributed to superior ductility, while for UFG steel, ductility was also good but because of deformation twinning. The transition of deformation mechanism from strain-induced martensite in commercial steel to twinning in UFG austenitic stainless steels is related to decrease in grain size, such that the austenite becomes more stable and twinning is the mode of plastic deformation that contributes to excellent ductility 
$[4,5]$.

\section{Conclusions}

(1) The UFG 316LN austenitic stainless steel with mean grain size of $2.0 \mu \mathrm{m}$ was successfully obtained using a combination of cold rolling (90\% reduction) and annealing $\left(900^{\circ} \mathrm{C}\right)$.

(2) The UFG 316LN austenitic stainless steel exhibited excellent mechanical properties of high yield strength and high plasticity.

(3) The high ductility of UFG 316LN austenitic stainless steel was due to twinning, while in the commercial steel, strain-induced $\alpha$-martensite contributed to high ductility.

\section{Acknowledgements}

Authors gratefully acknowledge the financial support from National Natural Science Foundation of China (No. 51501134). R.D.K. Misra gratefully acknowledges support from the National Science Foundation, USA through grant number DMR 1458074. 


\section{$\underline{\text { References }}$}

[1] L.P. Karjalainen, T. Taulavuori, M. Sellman, A. Kyröläinen. Some strengthening methods for austenitic stainless steels. steel Research Int. 79 (2008) 404-412.

[2] R.D.K. Misra, S. Nayak, S.A. Mali, J.S. Shah, M.C. Somani, L.P. Karjalainen. On the significance of nature of strain-induced martensite on phase-reversion- induced nanograined/ultrafine-grained austenitic stainless steel. Metall. Mater. Trans. A 41A (2010) 3-12.

[3] R.D.K. Misra, V.S.A. Challa, P.K.C. Venkatsurya, Y.F. Shen, M.C. Somani, L.P. Karjalainen. Interplay between grain structure, deformation mechanisms and austenite stability in phase-reversion-induced nanograined/ultrafine-grained austenitic ferrous alloy. Acta Mater. 84 (2015) 339-348.

[4] V.S.A. Challa, X.L. Wan, M.C. Somani, L.P. Karjalainen, R.D.K. Misra. Strain hardening behavior of phase reversion-induced nanograined/ultrafine-grained (NG/UFG) austenitic stainless steel and relationship with grain size and deformation mechanism. Mater. Sci. Eng. A 613 (2014) 60-70.

[5] V.S.A. Challa, X.L. Wan, M.C. Somani, L.P. Karjalainen, R.D.K. Misra. Significance of interplay between austenite stability and deformation mechanisms in governing three-stage work hardening behavior of phase-reversion induced nanograined/ultrafine-grained (NG/UFG) stainless steels with high strength-high ductility combination. Scripta Mater. 86 (2014) 60-63.

[6] A. Kisko, R.D.K. Misra, J. Talonen, L.P. Karjalainen. The influence of grain size on the strain-induced martensite formation in tensile straining of anaustenitic 
15Cr-9Mn-Ni-Cu stainless steel. Mater. Sci. Eng. A 578(2013) 408-416.

[7] P. Behjati, A. Kermanpur, A. Najafizadeh, H. S. Baghbadorani. Effect of annealing temperature on nano/ultrafine grain of Ni-free austenitic stainless steel. Mater. Sci. Eng. A 592(2014) 77-82.

[8] F.Y. Dong, P. Zhang, J.C. Pang, D.M. Chen, K. Yang, Z.F. Zhang. Optimizing strength and ductility of austenitic stainless steels through equal-channel angular pressing and adding nitrogen element. Mater. Sci. Eng. A 587 (2013) 185-191.

[9] X.H. Chen, J. Lu, L. Lu, K. Lu. Tensile properties of a nanocrystalline 316L austenitic stainless steel. Scripta Mater. 52 (2005) 1039-1044.

[10] M. Eskandari, A. Najafizadeh, A. Kermanpur. Effect of strain-induced martensite on the formation of nanocrystalline $316 \mathrm{~L}$ stainless steel after cold rolling and annealing. Mater. Sci. Eng. A 519 (2009) 46-50.

[11] B.P. Kashyap, K. Tangri. On the Hall-Petch relationship and substructural evolution in type 316L stainless steel. Acta metall. mater. 43 (1995) 3971-3981.

[12] H. Wu, F. Wu, S. Yang, D. Tang. The formation mechanism of austenite structure with micro/sub-micrometer bimodal grain size distribution. Acta metal. sinica 30 (2014) 269-274.

[13] D. N. Wasnik, I.K. Gopalakrishnan, J. V. Yakhmi, V. Kain and I. Samajdar. Cold rolled texture and microstructure in types 304 and 316L austenitic stainless steels. ISIJ Int. 43 ( 2003) 1581-1589.

[14] A. Hedayati, A. Najafizadeh, A. Kermanpur, F. Forouzan. The effect of cold rolling regime on microstructure and mechanical properties of AISI 304L stainless 
steel. J. Mater. Process. Technol. 210 (2010) 1017-1022.

[15] R. Ueji, N. Tsuchida, D. Terada, N. Tsuji, Y. Tanaka, A. Takemura, K. Kunishige. Tensile properties and twinning behavior of high manganese austenitic steel with fine-grained structure. Scripta Mater. 59 (2008) 963-966.

[16] S. Allain, J.-P. Chateau, O. Bouaziz, S. Migot, N. Guelton. Correlations between the calculated stacking fault energy and the plasticity mechanisms in Fe-Mn-C alloys. Mater. Sci. Eng. A 387-389 (2004) 158-162.

[17] T.-H. Lee, E. Shin, C.-S. Oh, H.-Y. Ha, S.-J. Kim. Correlation between stacking fault energy and deformation microstructure in high-interstitial-alloyed austenitic steels. Acta Mater. 58 (2010) 3173-3186.

[18] P.J. Brofman, G.S. Ansell. On the effect of carbon on the stacking fault energy of austenitic stainless steels. Metall. Trans. 9A (1978) 879-880.

[19] J. Talonen, H. Hänninen. Formation of shear bands and strain-induced martensite during plastic deformation of metastable austenitic stainless steels. Acta Mater. 55 (2007) 6108-6118.

[20] J.H. Jun, C.S. Choi. Variation of stacking fault energy with austenite grain size and its effect on the $\mathrm{M}_{\mathrm{S}}$ temperature of $\gamma \rightarrow \varepsilon$ martensitic transformation in Fe-Mn alloy. Mater. Sci. Eng. A 257 (1998) 353-356.

[21] R. Ueji, Y. Takagi, N. Tsuchida, K. Shinagawa, Y. Tanaka, T. Mizuguchi. Crystallographic orientation dependence of $\varepsilon$-martensite transformation during tensile deformation of polycrystalline 30\% Mn steel. Mater. Sci. Eng. A 576 (2013) 14-20. 
[22] I. Gutierrez-Urrutia, S. Zaefferer, D. Raabe. The effect of grain size and grain orientation on deformation twinning in a Fe-22 wt.\% Mn-0.6 wt.\% C TWIP steel. Mater. Sci. Eng. A 527 (2010) 3552-3560.

[23] P. Yang, Q. Xie, L. Meng, H. Ding, Z. Tang. Dependence of deformation twinning on grain orientation in a high manganese steel. Scripta Mater. 55 (2006) $629-631$.

[24] S. Takaki, K. Fukunaga, J. Syarif, T. Tsuchiyama. Effect of grain refinement on thermal stability of metastable austenitic steel. Mater. Trans. 45 (2004) 2245-2251.

[25] Y.-S. Jung, Y.-K. Lee, D.K. Matlock, M.C. Mataya. Effect of grain size on strain-induced martensitic transformation start temperature in an ultrafine grained metastable austenitic steel. Met. Mater. Int. 17 (2011) 553-556.

[26] K. Nohara, Y. Ono, N. Ohashi. Composition and grain size dependencies of strain-induced martensitic transformation in metastable austenitic stainless steels. J. Iron Steel Institute Japan 63(1977) 772-782. 
Table 1 Chemical compositions and SFE of the investigated steel (wt $\%$ ).

\begin{tabular}{cccccccc}
\hline $\mathrm{C}$ & $\mathrm{Si}$ & $\mathrm{Mn}$ & $\mathrm{N}$ & $\mathrm{Cr}$ & $\mathrm{Ni}$ & $\mathrm{Mo}$ & $\mathrm{SFE}, \mathrm{mJ} / \mathrm{m}^{2}$ \\
\hline 0.04 & 0.34 & 1.15 & 0.048 & 18.06 & 8.33 & 0.051 & 18.9 \\
\hline
\end{tabular}

Table 2 The mechanical properties and $\mathrm{M}_{\mathrm{d} 30}$ temperature of the investigated steels.

\begin{tabular}{cccccc}
\hline Steel & Mean grain & Mean yield & Mean tensile & Mean & $\mathrm{M}_{\mathrm{d} 30}$, \\
& size, $\mu \mathrm{m}$ & strength, $\mathrm{MPa}$ & strength, MPa & elongation, $\%$ & ${ }^{\circ} \mathrm{C}$ \\
\hline Commercial & 12.6 & 281 & 644 & 52 & 7.6 \\
UFG & 2.0 & 994 & 1161 & 40 & 0.1 \\
\hline
\end{tabular}



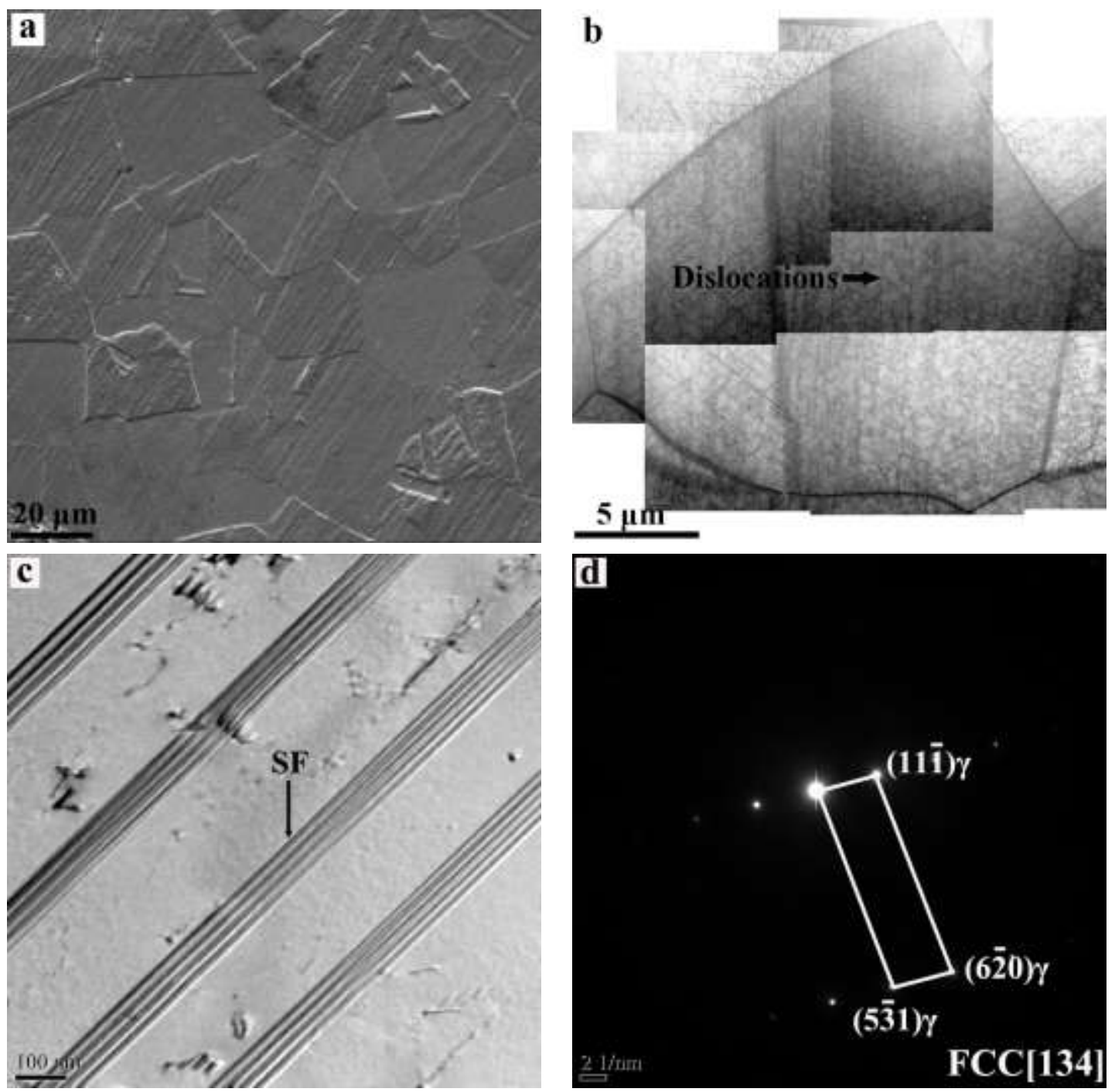

Fig. 1. (a) SEM and (b, c) TEM bright field micrographs of commercial $316 \mathrm{LN}$ austenitic stainless steel. (d) Selected area diffraction pattern taken from image (c). 


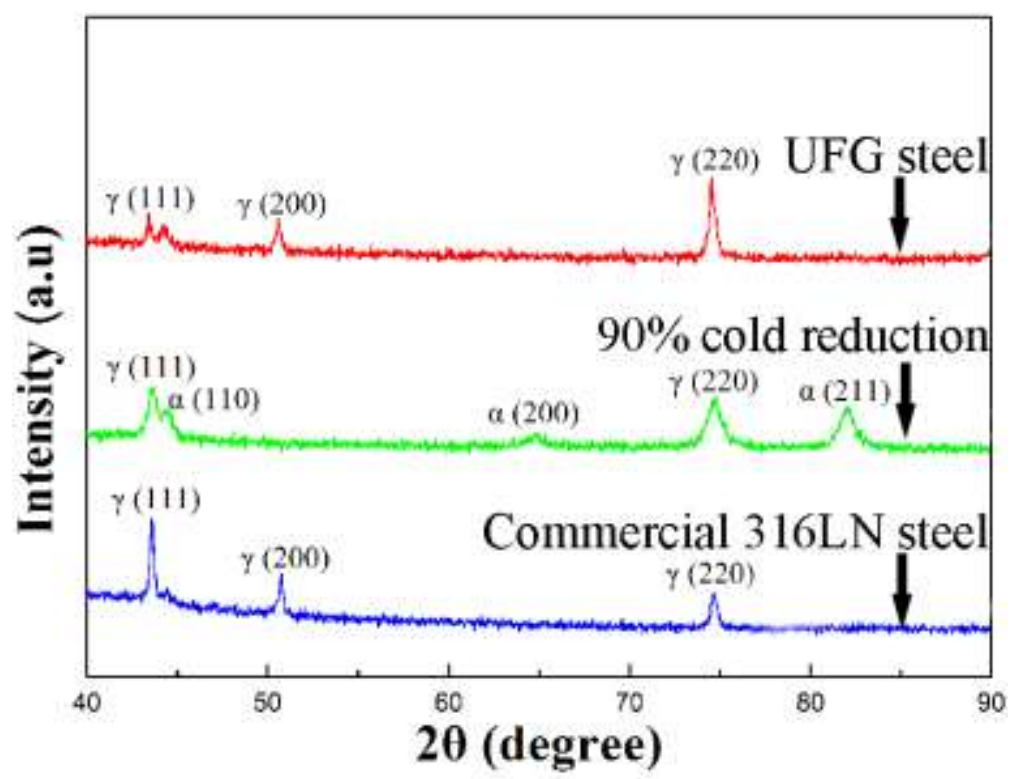

Fig. 2. XRD patterns of the 316LN austenitic stainless steels before, during and after phase reversion annealing treatment. 

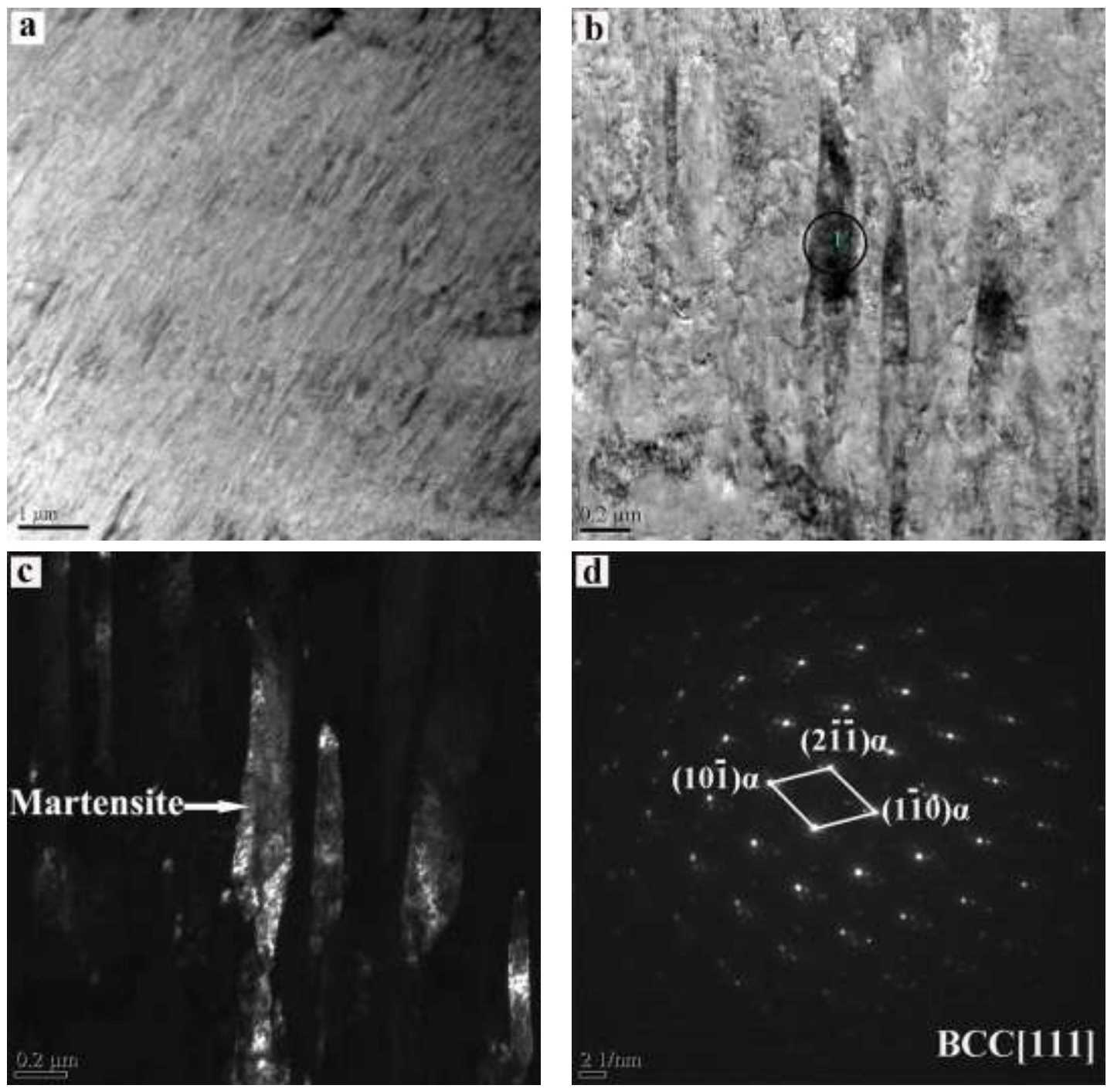

Fig. 3. TEM (a, b) bright and (c) dark field micrographs of $316 \mathrm{LN}$ austenitic stainless steels after $90 \%$ cold rolling reduction and (d) selected area diffraction pattern for area 1 in image (b). 

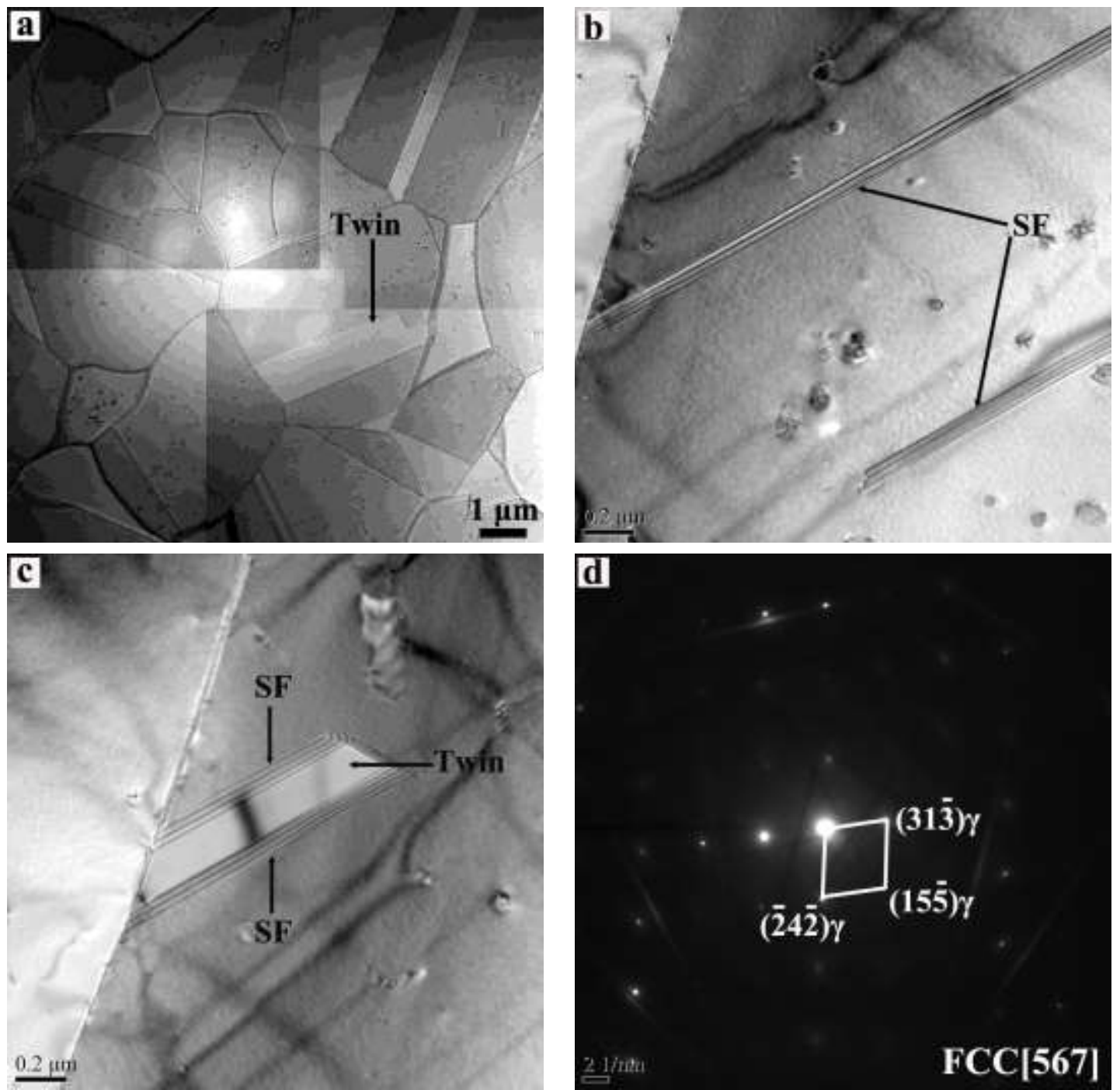

Fig. 4. (a, b, c) TEM bright field micrographs for 316LN austenitic stainless steels after $900{ }^{\circ} \mathrm{C}$ annealing treatment and (d) selected area diffraction pattern taken from the center of image (c). 

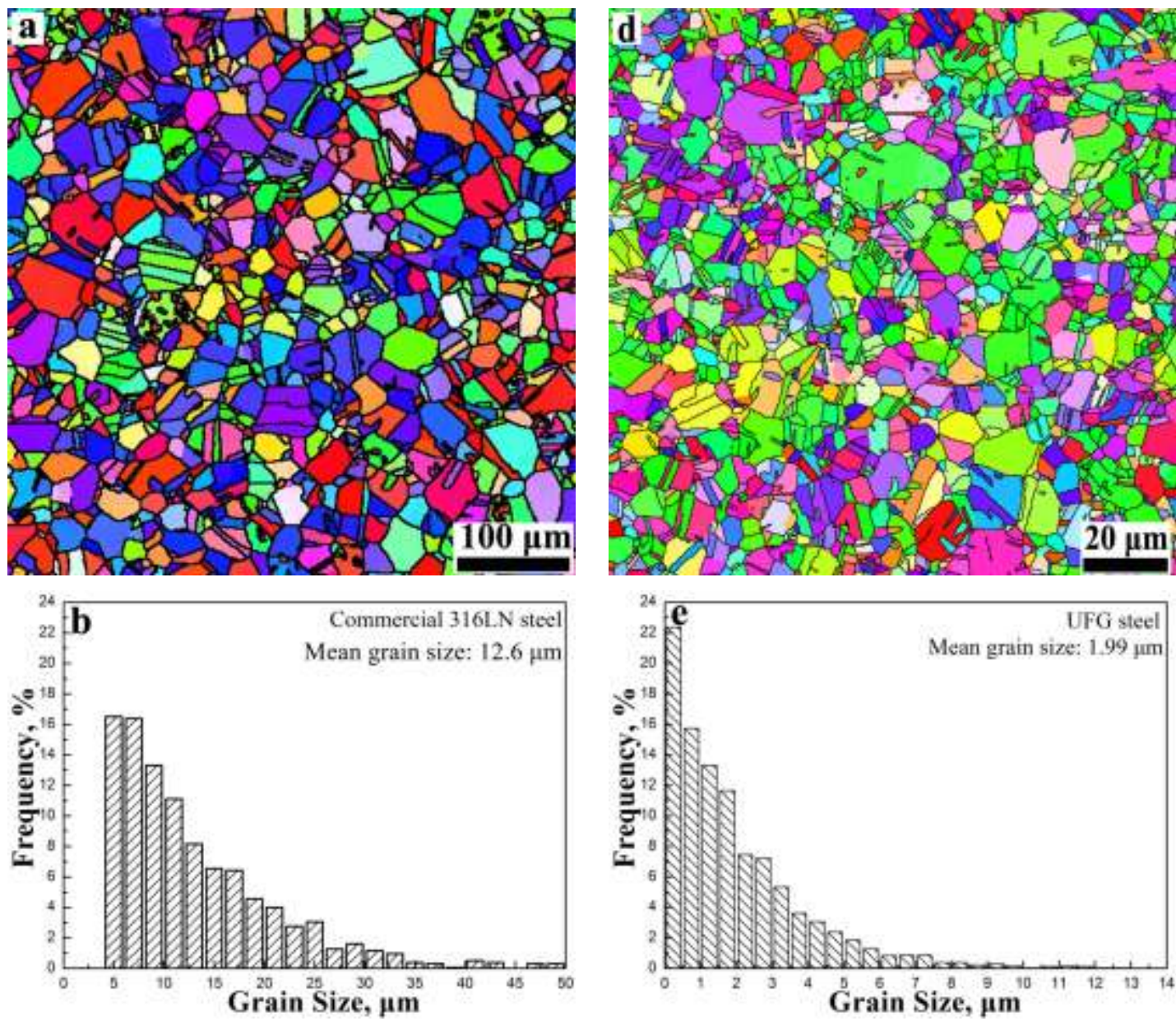

C Exp. densities (mud):
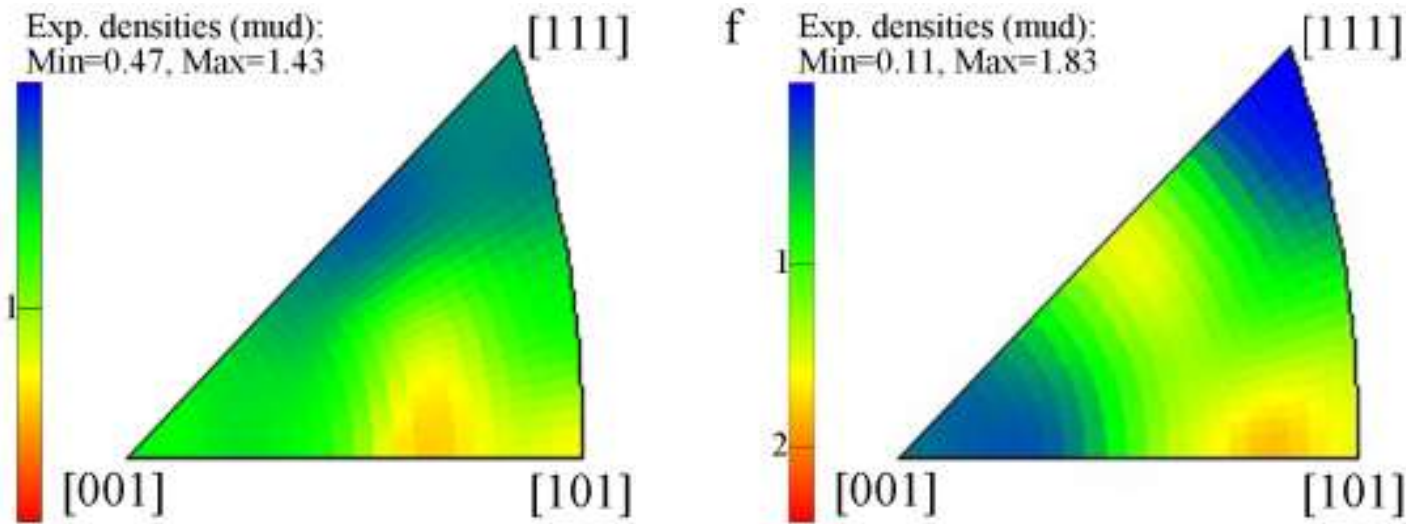

Fig. 5. (a,d) Orientation maps of samples, (b,e) statistical distribution of grain size and (c,f) inverse pole map of microstructure showing transverse direction orientation distributions in (a-c) commercial and (d-f) UFG 316LN steels. 

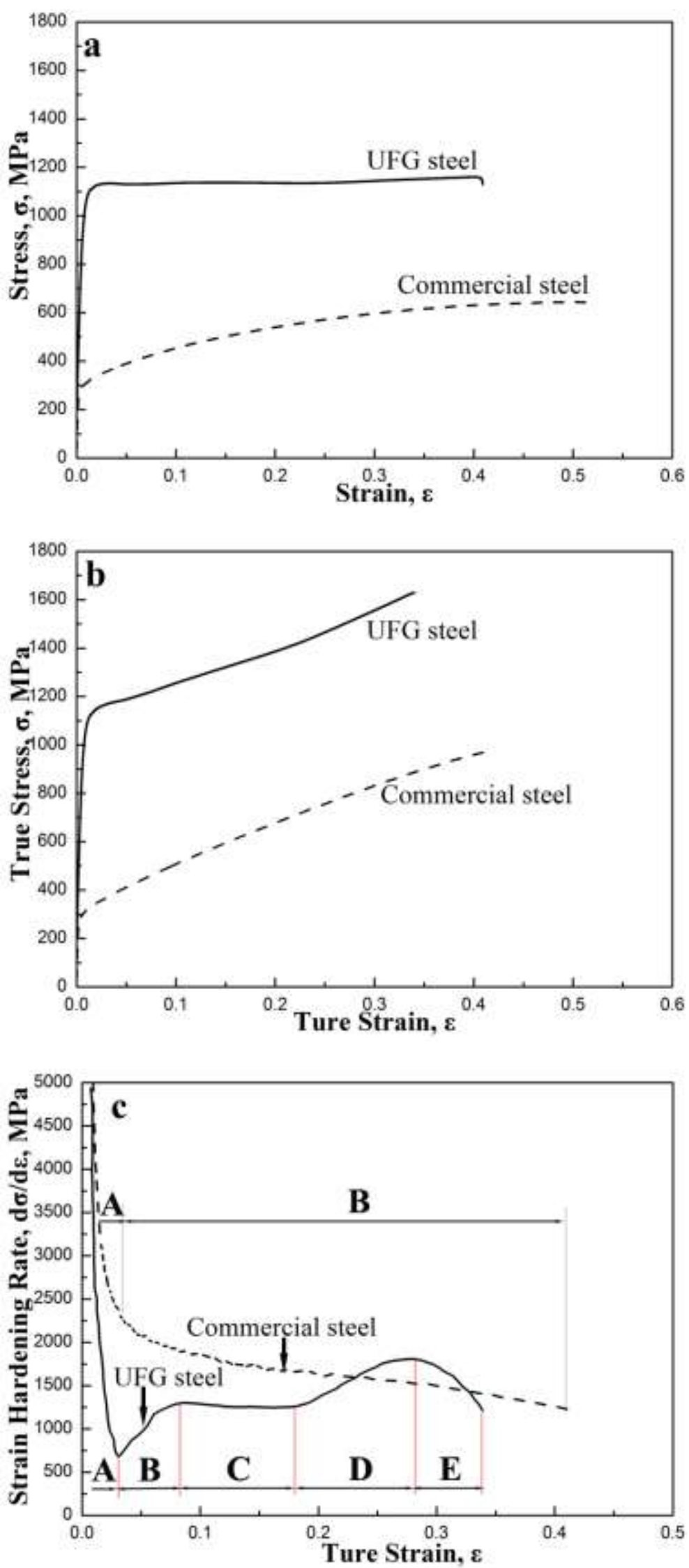

Fig. 6. (a) Engineering stress-strain, (b) true stress-strain and (c) strain hardening ratestrain plots for commercial and UFG 316LN austenitic stainless steels. 

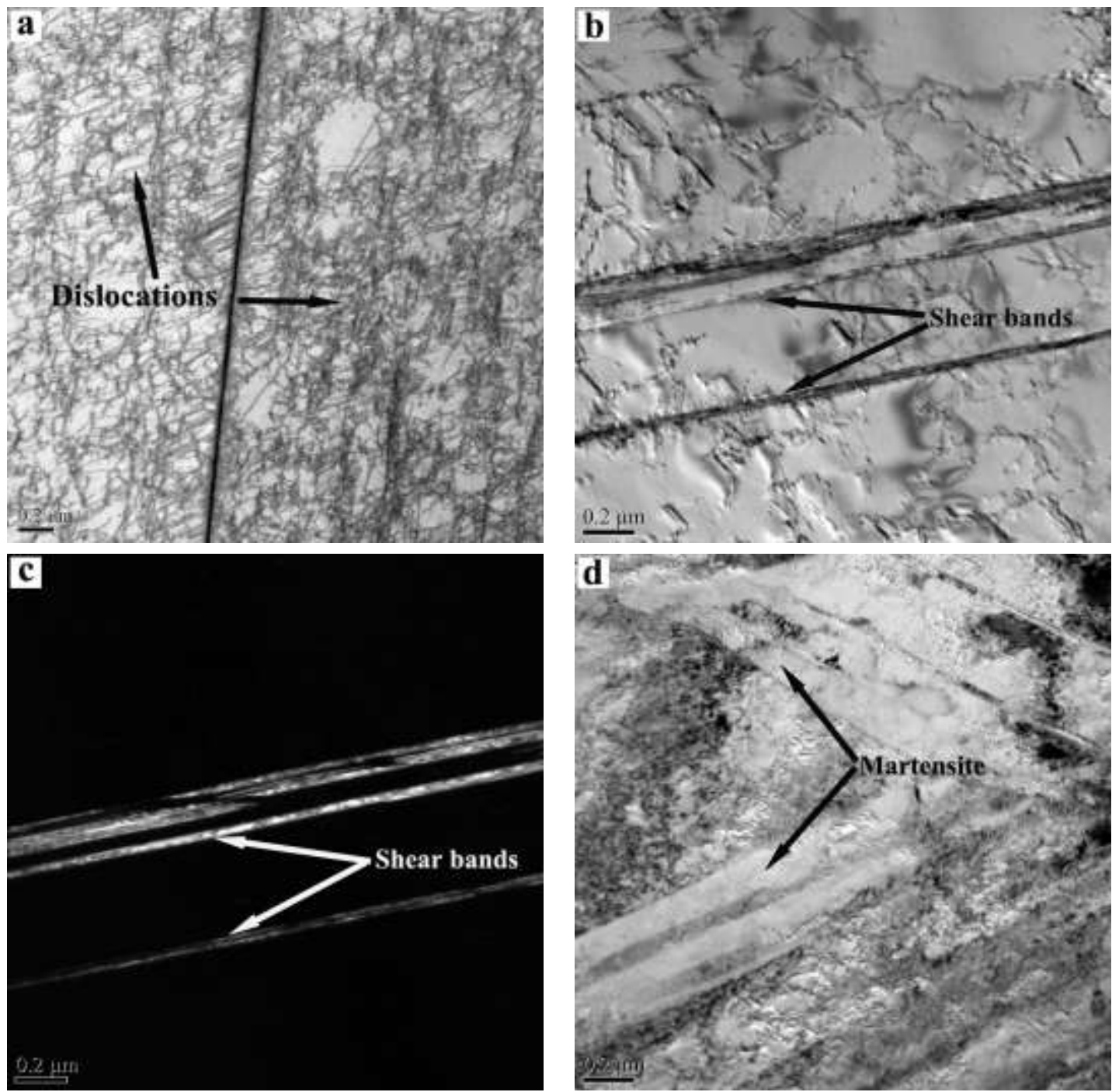

Fig. 7. Representative (a, b, d) bright and (c) dark field TEM micrographs of commercial 316LN austenitic stainless steel illustrating strain-induced deformation structure at 0.1 engineering strain. 

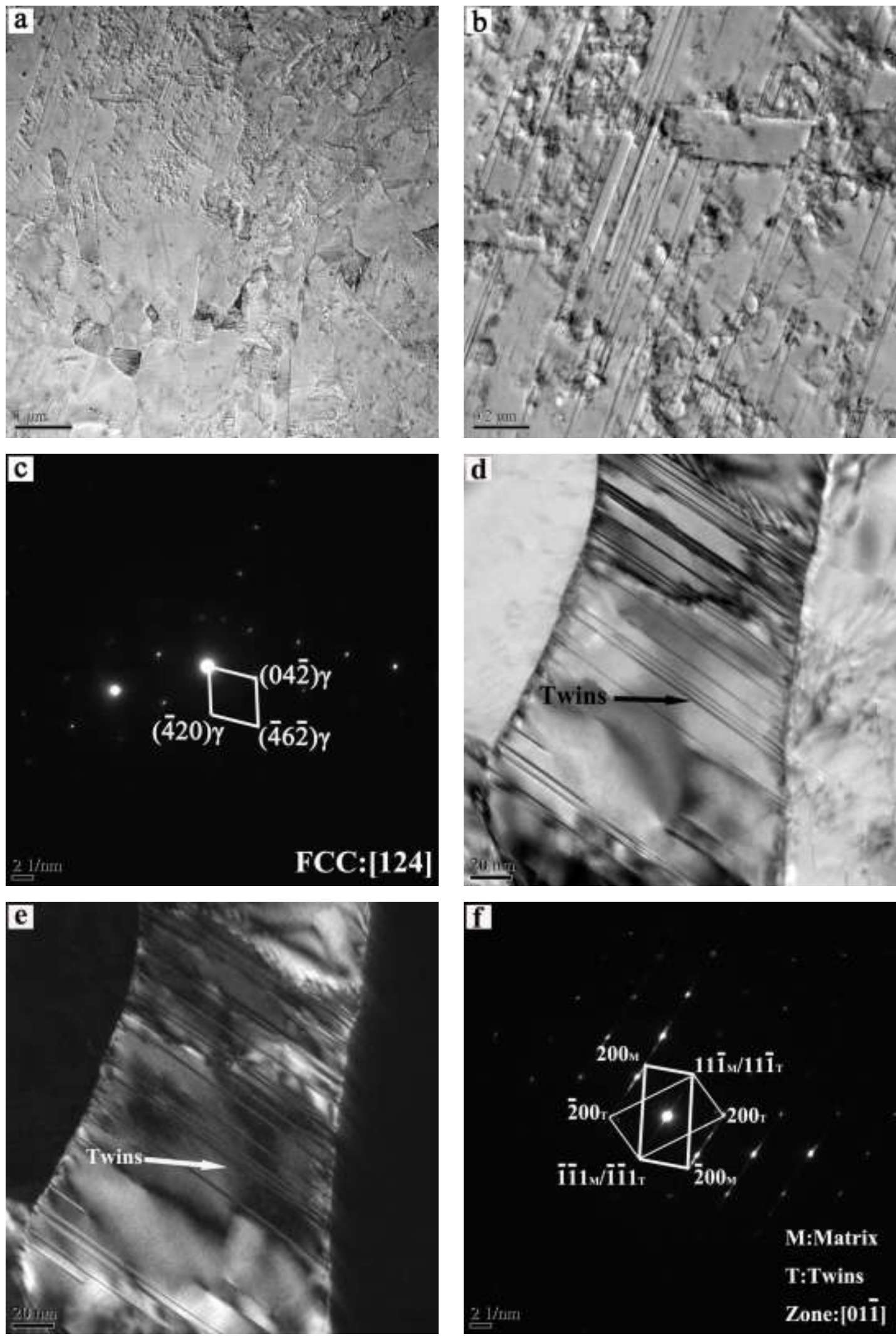

Fig. 8. Representative (a, b, d) bright and (e) dark field TEM micrographs of UFG 316LN austenitic stainless steel illustrating strain-induced deformation structure at 0.1 engineering strain, and (c) and (f) selected area diffraction pattern taken from images (b) and (d) respectively. 